\title{
Correction to: Atlas of Cardiac Catheterization for Congenital Heart Disease
}

Gianfranco Butera, Massimo Chessa, Andreas Eicken, and John D. Thomson

\section{Correction to:}

G. Butera et al. (eds.), Atlas of Cardiac Catheterization for Congenital Heart Disease, https://doi.org/10.1007/978-3-319-72443-0

This book was inadvertently published with patients' names in figures and videos for the following chapters
a. Chapter 1, Fig. 1.9
b. Chapter 20, Figs. 20.8, 20.12, 20.13, and all videos
c. Chapter 28, Fig. 28.12
d. Chapter 30, Video 1

Patient's names have been removed from the book.

The updated online version of these chapters can be found at https://doi.org/10.1007/978-3-319-72443-0_1 https://doi.org/10.1007/978-3-319-72443-0_20 https://doi.org/10.1007/978-3-319-72443-0_28 https://doi.org/10.1007/978-3-319-72443-0_30 